|Araştırma Makalesi / Research Article |

\title{
Verimlilik ve İnsan ilişkileri Söylemleri Arakesitinde Eğitim Yönetiminin Bilgi Temeli Oluşumu: Chester Barnard ve Etkileri
}

\section{Knowledge Basis of Educational Administration at the Intersection of Productivity and Human Relations Discourses: Chester Barnard and His Effects}

\section{Ünal Deniz ${ }^{1}$

Anahtar Kelimeler
chester barnard
eğitim yönetimi
eğitim yönetiminin bilgi
temeli
insan ilişkileri
verimlilik

\section{Keywords}

chester barnard

educational

administration

knowledge base of

educational

administration

human relations

productivity

Başvuru Tarihi/Received

09.04.2019

Kabul Tarihi /Accepted

24.10.2019
Öz

Bu araştırmanın amacı, eğitim yönetiminin bilgi temeli oluşumunda, bir yönetim bilimi temsilcisi olarak Chester Barnard'ın katkılarını ortaya koymaktır. Bu kapsamda, öncelikle yönetimin ayrı bir disiplin olarak ortaya çıkışını tetikleyen unsurlar ile eğitim yönetiminin bilgi temeli oluşumundaki gelişmeler ele alınmıştır. Ardından ise Chester Barnard'ın alanda ortaya koyduğu çalışmalar ve bu çalışmaların eğitim yönetimi alanına yansımaları incelenmiştir. Araştırmanın sonuçları, Chester Barnard'ın yaptığı kuramsal ve ampirik çalışmalar ile eğitim yönetiminde demokratikleşmenin entelektüel köklerinden birini oluşturduğu ve neoklasik döneme geçişte bir köprü görevi üstlendiğini göstermektedir. Ayrıca, Chester Barnard’ın Frederick Taylor'a ait bilimsel yönetim anlayışını ve Elton Mayo'nun insan ilişkileri yaklaşımını basit ve pragmatik bir şekilde birleştirdiği gözlemlenmiştir. Bu durumun özellikle eğitim örgütleri için daha uygulanabilir bir yönetim anlayışı ortaya koyduğu ve izleyen yıllarda hem teori hem de uygulama alanında eğitim yönetimini derin bir şekilde etkisi altına aldığı sonucuna varılmıştır.

\section{Abstract}

The aim of this research is to reveal the contribution of Chester Barnard as a management science representative in the formation of knowledge base of educational administration. In this context, firstly, the factors that triggered the emergence of management as a separate discipline and the developments in the formation of the knowledge base of educational administration were discussed. Then Chester Barnard's studies in the field and the reflections of these studies on the fields of educational administration were examined. The results of the study show that, Chester Barnard served as a bridge between classical term to neo-classical term by creating one of the intellectual roots of democratization in educational administration with his theoretical and empirical studies. In addition, it was observed that Chester Barnard combined the scientific management approach of Frederick Taylor and Elton Mayo's approach to human relations in a simple and pragmatic way. It has been concluded that this situation has provided a more applicable management approach especially for educational organizations and it has deeply influenced educational administration in both theory and practice in the following years.

${ }^{1}$ Hacettepe Üniversitesi, Eğitim Fakültesi, Eğitim Bilimleri Bölümü, Ankara, TÜRKiYE; https://orcid.org/ 0000- 0001- 7447- 6050

Alıntı/Citation: Deniz, Ü. (2020). Verimlilik ve insan ilişkileri söylemleri arakesitinde eğitim yönetiminin bilgi temeli oluşumu: Chester Barnard ve etkileri. Kastamonu Education Journal, 28(3), 1209-1219. doi: 10.24106/kefdergi.3709 


\section{Extended Abstract}

\section{Introduction}

Since the past, there has always been a relationship between sciences. Comparing other sciences, the natural sciences with having more ancient roots played a guiding role for many other sciences which emerged after itself. Compared to natural sciences, it can be said that social sciences are highly selective as well as being more limited in terms of producing new information. This is also the case for the science of management included in social sciences and emerged in scientifically over the last few centuries. In other words, while science of management being influenced by different sciences, it had tried to form its own theoretical framework within the scientification process (Beycioğlu and Dönmez, 2006; Çalık, 1997). In this context, science of management firstly based on Taylor's scientific management approach under the influence of the culture of efficiency. It was later influenced by the approach of human relations in science management led by Chester Barnard.

Having served as a senior executive for most of his life, Barnard has made an important contribution to the development of the science of management by theorizing his experiences and observations based on practice. Undoubtedly, the originality of his thinking is at the heart of his important contributions. In fact, although producing his works occurred at the same time as classic periods, he bridged to neoclassic period with his new and human-oriented views on motivation, authority, leadership, social responsibility, ethics and conflict resolution subjects. Although he gave importance to the issues of communication and cooperation, he brought a new understanding to the concept of authority in classical management theory with his theory of acceptance. Being interrelatedness of organization subsystems, thus he revealed that the organization should be designed and handled as a whole (Sucu, 2000). The ideas and opinions in his book, named as The Functions of the Executive, going beyond the human relationship approach had extended to ideation of modern management and even to the system approach maturing in 1970s (Baransel, 1993; Collins and Porras, 2002).

The reason why Barnard was so important in the first half of the $20^{\text {th }}$ century was that he created his studies with an original perspective by avoiding mediocrity and uniformity in his ideas (English, 2006). Until Barnard, studies on principles and process of organization had been defined just qualitatively without empirical base (Gehani, 2002). However, Barnard changed this situation by supporting his studies with social and natural sciences (Bursalıoğlu, 2014). Thus, by presenting a coherent and systematic management theory which provided wide reputation to him, he led to improvement of seven important organizational fields. Besides, he influenced major management scientists such as Simon and Williamson (Levitt and March, 1990). As a result of this influence, by initiating the transition process of behavioral and management sciences, Simon influenced to future with his modern and postmodern approaches (Ögüt ve Öztürk, 2007). According to Perrow (2014), Barnard's studies dominated the following thirty years of organizational theory. In addition to this, Barnard explained many sociological concepts by using his experiences gained from his own daily life (Barnard, 1976). In this aspect, sometimes he was remembered as sociologist without portfolio (Shapiro, 2006, p. 100).

\section{Purpose and Importance}

Chandran (2010) states that the appropriateness of the principles and theories developed by Barnard should be re-examined from the perspective of contemporary managers and leaders. For him, Barnard still represents an important link to the thought of management and leadership. Because, on the one hand, Barnard tried to understand how to preserve the existence of the organization through the protection of the balance within the institution and the examination of the external forces on the other. In response to this, it has revealed that through the official organization, both the existence of the organization and its effectiveness and productivity can be achieved. In other words, Barnard analyzed the functions carried out by the administrators as a unified system and tried to adapt this to all levels of the organization (Barnard, 1976; Nikezić, Dželetović and Vučinić, 2016; Wren and Bedeian, 2009). All these reveals, the importance of the fundamental ideas contained in the studies of Barnard. The aim of this study is to reveal the contributions of Chester Barnard as a management science representative in the formation of knowledge base of educational administration. In the literature, there are several studies related to Barnard's contributions to management science (Chandran, 2010; Nikezić et al., 2016; Öğüt and Öztürk, 2007; Wren and Bedeian, 2009) but there is no study directly examining this effects on educational administration. With this study, it is examined how Barnard, which is one of the intellectual roots of democratization in educational administration, has an effect on that with his theoretical and empirical studies.

\section{Result and Discussion}

Intrinsically, it can be stated that educational organizations are based on human relations. Being ignored human and human relations in classical management approach also caused education organizations to be seen as just working for efficiency understanding. However, Hawthorne studies showed that the situation was not just structure even for business organizations, brought new movement for organizations. Within a short period of time after this movement, it is seen that the concepts such as motivation, authority, leadership, social responsibility, ethics, etc., which are prominent in the human relations approach represented by Barnard in the field of management had entered into the literature on educational administration. All of these revealed how Barnard, who developed a simple and pragmatist synthesizes of Frederick Taylor's scientific management school and of Elton Mayo's human relations approach, affected scientific process of educational administration. 


\section{GíRiş}

Geçmişten beri bilimler arasında bir ilişki her zaman için var olmuştur. Diğer bilimlere kıyasla kökleri daha eskilere dayanan doğa bilimleri, kendisinden sonra ortaya çıkacak birçok bilim için yönlendirici bir rol oynamıştır. Bu noktada diğer bilimler genellikle doğa bilimleri tarafından ortaya atılan bilgileri inceleme ve görüş bildirme yolunu benimsemiştir. Ancak bu durum sosyal bilimlerde farklı bir şekilde kendini göstermektedir. Doğa bilimlerine nazaran yeni bilgiler üretme konusunda biraz daha sınırlı olan sosyal bilimlerin aynı zamanda oldukça seçici olduğu söylenebilir. Sosyal bilimler içerisinde yer alan ve bilimsel olarak son birkaç yüzyıl içerisinde ortaya çıkan yönetim bilimi için de aynı durum söz konusudur. Yani yönetim bilimi, bir taraftan farklı bilim dallarından etkilenmiş, diğer taraftan ise bilimselleşme süreci içerisinde kendi kuramsal yapısını oluşturmaya çalışmıştır (Beycioğlu ve Dönmez, 2006; Çalık, 1997). Bu bağlamda yönetim bilimi ilk olarak, verimlilik kültünün etkisi altında Taylor'un bilimsel yönetim anlayışına göre temellenmiştir. Sonraki süreçte ise Barnard'ın önderliğini yaptığı yönetim biliminde insan ilişkileri yaklaşımının etkisi altına girmiştir.

Barnard'ın 20. yüzyılın ilk yarısında bu kadar önem arz etmesinin nedeni ortaya koyduğu fikirlerde sıradanlık ve tekdüzelikten uzak durarak, orijinal bir bakış açısına sahip eserler oluşturmasıdır (English, 2006). Barnard'a kadar örgütün ilke ve süreçlerine ilişkin yapılan çalışmalar ampirik temel olmadan sadece niteliksel açıdan tanımlanmıştır (Gehani, 2002). Ancak Barnard çalışmalarını sosyal bilimler ve doğa bilimleri ile destekleyerek, bu durumu değiştirmiştir (Bursalıoğlu, 2014). Böylece geniş bir üne sahip olmasını sağlayan tutarlı ve sistemli bir yönetim teorisi ortaya koyarak, yedi önemli örgüt alanının gelişmesini sağlamıştır. Ayrıca ardından gelen Simon ve Williamson gibi önemli yönetim bilimcilerini etkisi altına almıştır (Levitt ve March, 1990). Simon, bu etkilenmenin sonucunda davranış ve yönetim bilimlerinin gelişmesinde geçiş sürecini başlatarak, modern ve post-modern yaklaşımlarıyla geleceğe ışık tutmuştur (Ögüt ve Öztürk, 2007). Perrow'a (2014) göre Barnard'ın çalışmaları örgütsel teorinin gelecekteki otuz yılına ağırlığını koymuştur. Bununla birlikte Barnard, günlük yaşam deneyimlerini kullanarak birçok sosyolojik kavramı açıklamıştır (Barnard, 1976). Bu yönüyle zaman zaman portfolyosuz sosyolog olarak da anılmıştır (English, 2006; Shapiro, 2006).

Chandran (2010), Barnard tarafından geliştirilen ilke ve teorilerin uygunluğunun çağdaş yöneticiler ve liderler perspektifinden yeniden incelenmesi gerektiğini belirtmektedir. Ona göre, Barnard hala yönetim ve liderlik düşüncesi için önemli bir bağlantıyı temsil etmektedir. Çünkü Barnard, bir yandan kurumun içerisinde dengenin korunması, diğer yandan dış kuvvetlerin incelenmesi yoluyla örgütün varlığının nasıl korunacağını anlamaya çalışmıştır. Buna cevaben, resmi örgütlenme yoluyla hem örgütün varlığının hem de etkililiğinin ve verimliliğinin sağlanabileceğini ortaya atmıştır. Diğer bir deyişle, Barnard yöneticiler tarafından örgüt içinde yerine getirilen işlevleri birleşik bir sistem olarak analiz etmiş ve bunu örgütün tüm seviyelerine uyarlamaya çalışmıştır (Barnard, 1976; Nikezić, Dželetović ve Vučinić, 2016; Wren ve Bedeian, 2009). Tüm bunlar, Barnard'ın ortaya koyduğu eserlerde yer alan temel düşüncelerin önemini ortaya koymaktadır.

Bu kapsamda ele alınan çalışmanın amacı, eğitim yönetiminin bilgi temeli oluşumunda bir yönetim bilimi temsilcisi olarak Barnard'ın katkılarını ortaya çıkarmaktır. Literatürde, Barnard'ın yönetim bilimine katkılarını ele alan çeşitli araştırmalar (Chandran, 2010; Nikezić vd., 2016; Öğüt ve Öztürk, 2007; Wren ve Bedeian, 2009) bulunmakla birlikte eğitim yönetimi üzerindeki etkilerini doğrudan inceleyen bir araştırma bulunmamaktadır. Oplatka (2016) eğitim yönetimi alanının geliştirilmesi, iyileştirilmesi ve alandaki entelektüel tartışmaların yansımalarının görülebilmesi için kuramsal incelemelere ihtiyaç olduğunu vurgulamıştır. Yapılan bu çalışmayla birlikte, yaptığı kuramsal ve ampirik çalışmalarla eğitim yönetiminde demokratikleşmenin entelektüel köklerinden birini oluşturan Barnard’ın eğitim yönetimini nasıl etkisi altına aldığı incelenecektir. Ayrıca araştırmanın eğitim yönetiminin kuramsal temellerinin anlaşılmasına katkı sağlayacağı düşünülmektedir.

\section{Yönetim Biliminin Doğuşu}

Yönetimin bir bilim olarak ortaya çıkışında, üç önemli etken söz konusudur. Bunlardan ilki, Adam Smith'in 1776'da yayımladığı Ulusların Zenginliği adlı eserinde üretim faktörleri arasında müteşebbisin yer alması konusundaki fikirleridir. İkincisi, James Watt'ın 1765'de buhar makinesini bularak, enerji kaynağı alanında bir devir açmasıdır. James Watt'ın buhar enerjisini uygulamaya koymasıyla başlayan sanayi devrimi büyük endüstrilerin doğmasına neden olmuştur. Üçüncü olarak ise Fransız ihtilali'nin toplumlarda etkili olması sonucu bilinçli işletme kavramının ortaya çıkışıdır. Bu durum, yönetim ve örgüt kavramlarının bilinçli olarak kullanılmasını doğurmuştur (Koçel, 2018). Bu noktada, özellikle Fransız İhtilali'nin sanayi toplumunun temel felsefesi olan liberalizmi yaratması ve liberal düşüncenin geri dönülmezliğini kanıtlaması oldukça önemlidir (Dalay, 2001). Sonuç olarak, yönetim biliminin doğuşunda ekonomik, teknolojik ve politik alanda yaşanan gelişmeler belirleyici olmuştur. Bu üç önemli olayla birlikte bilinçli bir işletme kavramı ve buna bağlı olarak yönetim anlayışının geliştiği öne sürülebilir.

Sanayi Devrimi ortaya çıkmadan önce işletmeler daha çok insan emeği, hayvan gücü veya su-rüzgar gücü gibi doğal enerji kaynakları kullanarak tarımsal üretim ve satış yapan ekonomik birimlerdir. Buharlı makinelerin icat edilerek endüstride kullanılmasıyla birlikte işletmecilik anlayışı üretim, yöntem ve teknik anlamında bir değişime uğramıştır. Sanayi Devrimi olarak anılan bu olay üretim, yöntem ve teknik boyutlarında kendini göstermiştir (Baransel, 1993). ilkel üretim yöntemleri yerini daha bilimsel ve gelişmiş yöntemlere bırakmış, emek yoğun işletmelerin yanında sermaye yoğun işletmeler de ortaya çıkmıştır. Böylece pazar için bolca üretim söz konusu olmuştur (Akat ve Budak, 2002). Ayrıca girişimcinin fonksiyonları arasında yer alan yönetimin, belli bir ücret karşılığı yönetim işlevini yerine getiren profesyonel yöneticilere devredilmesi sebebiyle sahiplik ile yöneticiliğin birbirinden ayrılması durumu söz konusu olmuştur (Ertürk, 2018). Bu durum, kaliteli yönetici talebinin artmasına, yönetilenle rin örgüt içerisindeki statülerinin değişmesinde ve bunlara bağlı olarak yönetimin ayrı disiplin haline gelmesinde öncü olmuştur. Diğer

| Kastamonu Eğitim Dergisi, 2020, Vol. 28, No. 3| 
taraftan, kamu yönetiminin siyaset biliminden ayrı olarak özerk bir inceleme sahasına dönüşmesi yönetim biliminin gelişimini hızlandırmıştır. Özellikle Prusya'da 18. yüzyılda Kameral Bilimler Enstitüsünün açılması ile ABD'de W. Wilson'un (1887) kamu yönetiminin ilkelerini tartışmaya açtığı The Study of Administration isimli makalesi önemli rol oynamıştır (Özdemir, 2019).

Bilimsel yöntemlere yöneliş ile birlikte Taylor, Fayol, Weber gibi yönetim düşünürleri ve onların yönetim yaklaşımları yönetimi bilimsel bir disiplin haline dönüştürmüştür (Robbins ve Judge, 2015). Taylor, Fayol ve Weber'in temsil ettiği ve klasik yaklaşım olarak adlandırılan bu yaklaşım, insan organizmasını basit bir makine, insanlardan oluşan geleneksel örgüt yapısını da benzer şekilde yine makine (teknik bir sistem) olarak görmektedir (Başaran, 1989). Bu yaklaşıma klasik denmesinin nedeni yönetim düşüncesine uzun zaman hakim olmuş ve yerleşmiş olmasıdır. İinci olarak, davranışsal yaklaşım olarak da adlandırılan neoklasik yaklaşım psikoloji, sosyoloji ve sosyal psikoloji alanlarındaki bulguların ve geliştirilen yöntemlerin, yönetimin bir parçası olan örgütsel davranış biçimlerinin anlaşılması için kullanılmasına dayanmaktadır (Şimşek ve Çelik, 2018). İnsan davranışı, kişilerarası ilişkiler, grup davranışları, informel (biçimsel olmayan) örgüt, algılama ve tutumlar, motivasyon, liderlik ve örgütlerde değişim bu yaklaşımın incelediği konulardır (Eren, 2017). Üçüncü olarak, modern yaklaşımlar içerisinde yer alan sistem yaklaşımı, doğa bilimleri (biyoloji) alanında ortaya çıkan genel sistem teorisini işletme örgütlerine yansıtarak, işletmelerin açık sistemler olduğunu kabul etmiştir. Bir diğer modern yaklaşım olan durumsallık yaklaşımı, yapısal olarak öngörülemeyen durumlara en uygun örgüt modelinin uygulanmasıdır. 1970'li yıllardan sonra yönetim alanında yapılan araştırma ve çalışmalar, post-modern yaklaşımlar olarak ifade edilmektedir. Bunlar arasında toplam kalite yönetimi, değiş̧im mühendisliği, öğrenen örgüt gibi farklı konular göze çarpmaktadır (Hitt, Black ve Porter, 2011; Memduhoğlu ve Yılmaz, 2013).

\section{Eğitim Yönetiminin Bilgi Temeli}

Epistemolojik ve ontolojik kökleri bulunan eğitim yönetimi alanının ilk kez bilimsel bir disiplin olarak ele alınması 20. yüzyıl başlarında ABD'de gerçekleşmiştir (Eacott ve Evers, 2015). Özdemir (2011) eğitim yönetiminin bilimsel bir disiplin olarak ele alınmasında, 20. yüzyılda ortaya çıkan ekonomik, sosyal ve siyasi gelişmeler ile birlikte okul sayısının artması ve eğitim hizmetinin kamusal bir alan haline gelmesinin önemli bir rol oynadığını öne sürmektedir. Amerika'da filizlenen ve gelişme gösteren eğitim yönetimi alanı, sonraki yıllarda başta İngiltere olmak üzere bazı Avrupa ülkelerine de sıçrayarak, küresel ölçekte yayılma eğilimi içerisine girmiştir (Oplatka, 2016). Bu dönem içerisinde meydana gelen çeşitli gelişmeler, eğitim yönetiminin bilimsel bir inceleme sahasına dönüşmesine önemli katkı sunmuştur (Özdemir, 2018). Oysa 1900'lü yılların başlarına kadar eğitim yönetimine ilişkin görüşler yalnızca filozofların düşünceleriyle sınırlı kalmış ve eğitim olgusu genellikle felsefe alanında tartışılmıştır. Dolayısıyla bu dönemde eğitim yönetimi alanı bağımsız bir bilim olmaktan ziyade yöneticilerin kişisel deneyimlerine göre sundukları tavsiyelere göre şekillenmiştir (Heck ve Hallinger, 2005).

Eğitim yönetiminin bilgi temeli oluşumundaki gelişmelerden ilk etmen, eğitimin kendisinin bir bilim olma yolunda attığı adımdır. 1950'li yılların sonrasında yaşanan bazı gelişmeler eğitimin modern bilimin konusu haline gelmesini sağlamıştır. Şüphesiz bunda insanların nasıl öğrendikleri üzerine yapılan bilimsel çalışmalar önemli bir rol oynamıştır (Özdemir, 2018). Örneğin; Cattell öğrenmenin doğasına ilişkin yürüttüğü çalışmalarda elde ettiği sonuçları eğitim alanına taşıyarak yeni bir tartışma konusu başlatmıştır. Ardından gelen öğrencisi Thorndike öğrenme üzerinde pekiştireçlerin önemli bir etkiye sahip olduğunu ortaya koyan etki yasasını geliştirmiştir. Bu şekilde bilimsel karaktere bürünen eğitim faaliyetleri, Amerikan eyaletlerinde bilimsel esaslara dayalı olarak eğitim veren sosyal bir bilime dönüşmüştür. Psikoloji ve istatistik alanlarının gelişimleriyle kendisini bir bilim haline dönüştürme dinamizmini elde eden eğitim bilimi kısa süre içerisinde eğitim yönetimini de etkisi altına almıştır (Özdemir, 2018). Bu süreçten itibaren eğitim yönetimi alanında, kamu okullarının örgütlenmesi ve yönetilmesine odaklanan derslerin içeriği ve yöntemi değişmeye başlamıştır (Özdemir, 2019). Bu durum, eğitim yönetimi alanının akademik bir disiplin olarak gelişimini hızlandırmıştır.

Eğitim yönetiminin bilimleşmesine katkı sunan ikinci etmen ABD'de 1900'lerin başında ivme kazanan ve 1929 yılında patlak veren büyük buhrana kadar geçen süreçteki verimlilik söylemidir. Öğrencilerin akademik performanslarını değerlendirmek için geliştirilen ölçekler, Amerikan eğitim sistemindeki verimlilik vurgusunun arka planında önemli bir rol oynamıştır. Okulların ve okul sistemlerinin verimliliği konusu kamuoyunun dikkatini çektiğinden, bu alanda önde gelen isimler okul ve okul sistemleri üzerine geniş kapsamlı saha çalışmaları yürütmüştür. Tüm bu çalışmaların temel amacı, okullarda mali yönden disiplinin sağlanması olmuştur (Hallinger ve Chen, 2015; Özdemir, 2018). 20. yüzyıl başlarında verimlilik üzerinde çalışmalar yapmış olan Payne, Bobbitt ve Cubberley başta olmak üzere dönemin önde gelen eğitimcileri temel olarak Taylor'un ortaya koyduğu bilimsel yönetime ilişkin görüşlerini okula uyarlamaya çalışmıştır (Aktan, 2015; Eacott, 2015; Lunenburg ve Ornstein, 2012). Eğitim yönetimi alanının bu ilk kuşak araştırmacılarının odaklanmış oldukları temel nokta, alanın bilimsel temellerininin ortaya konulmasıdır. Nitekim 20. yüzyıldan itibaren eğitim literaründeki çalışmalar incelendiğinde, günümüzde de etkisini devam ettiren bilimsel yönetim ilkelerinin yansımaları görülmektedir (Watkins, 1983).

Eğitim yönetiminin bilgi temelindeki gelişimini hızlandıran üçüncü ve son etmen ise yönetim biliminin etkileridir. Yönetsel faaliyetin bilimsel yöntem ve ilkelere dayalı olarak yürütülmesi düşüncesindeki öncü çabalar Taylor tarafından başlatılmıştır. Bu dönemde eğitim yönetimi alanı kamu ve işletme yönetimindeki gelişmelerin etkisiyle daha çok Taylorist bir yaklaşımla kavranmaya çalışılmıştır (English, 2002). Daha sonra 1930'lu ve 1940'lı yıllarda verimlilik odaklı yaklaşımlar eleştirilerek, örgütsel süreçlerde insan ilişkileri odaklı yeni bir yönetsel yaklaşım benimsenmiştir (Özdemir, 2017; Özdemir, 2018). Aslında, 1940'ların ortalarından bu yana, eğitim yönetimi üzerine yazılan kitapların ana teması eğitim ve okul yönetiminde insan ilişkileri olmuştur (Griffiths, 1956; Mort ve Ross, 1957; Özdemir, 2017; Yauch, 2010). Bu dönemde en önemli köşe taşlarından biri olarak karşımıza Barnard çıkmaktadır. Barnard yönetsel düşüncenin evrimine insan odaklı yaklaşımıyla oldukça önemli bir katkıda bulunmuştur. Barnard’ın

| Kastamonu Eğitim Dergisi, 2020, Vol. 28, No. 3| 
yönetim alanında ortaya koyduğu çalışmalara geçmeden önce, Barnard’ın çalışmalarının daha iyi anlaşılabilmesi için takip eden bölümde hayatı hakkında kısa bir bilgi sunulmuştur.

\section{Chester I. Barnard}

Barnard 7 Kasım 1886 yılında, Massachusetts'de doğmuştur. Kolej yıllarını başarıyla tamamladıktan sonra 1906 yılında Harvard Üniversitesi'nden burs kazanarak ekonomi bölümünde eğitime başlamıştır (Wren, 2010). Üniversite eğitiminin son dönemlerinde teorik sınavını geçtiği bir derste uygulama bilgisinin eksik olması nedeniyle başarısız olmuştur. Teorik kısmını geçtikten sonra uygulama kısmını almanın gereksiz olduğunu düşünen Barnard, 1909 yılında üniversiteyi terk etmiştir (Öğüt ve Öztürk, 2007). Devam eden yılda Amerikan Telefon Telgraf Şirketi'nde işe girmiştir. Buradaki işinde hızlı denilebilecek bir biçimde yükselerek, 1922 yılında başkan yardımcısı olmuştur (Yearley, 2015). 1926 yılında Amerika Telefon Telgraf Şirketi'nden Bell System'e transfer olan Barnard, 1927 yılında bu şirketin Başkanlığına getirilmiştir. 1948 yılına kadar çalışma hayatına bu şirkette devam eden Barnard, bu yıldan itibaren Rockefeller Derneği'nin Başkanlığı için Bell System'deki işinden ayrılmıştır (English, 2006). Barnard, 1952 yılında emekliye ayrılarak aktif çalışma yaşamını tamamlasa da 1961 yılında New York'da yaşamını yitirene kadar birçok topluluk ve eğitim örgütlerinde çalışmalarına devam etmiştir (Wren, 2010).

Barnard'ın günlük hayatta sahip olduğu pratiğe dayalı geniş bilgi, onun kapsamlı bir bilgi birikimine sahip olmasını sağlamıştır. Sahip olduğu bu birikimini kaleme aldığı eserlere de yansıtarak, deneyime dayalı analizlerini gerçeğe dayalı bir bakış açısıyla işletme ve kamu yöneticilerine aktarmıştır (Öğüt ve Öztürk, 2007; Wolf, 1974, 1994). Barnard’ın eserleri çok detaylı bilgiler içermemesine rağmen ortaya koyduğu çalışmalardaki nitelikli düşüncelerden dolayı asıl popülerliğini kazanmıştır (English, 2006). Aslında, O'Connor (2012, 2013), Barnard'ın deneyimlerine dayanarak yeni bir organik uygulamalı sosyal bilim geliştirdiğini savunmaktadır. Barnard'ın 1938 yılında yayımlandığı The Functions of the Executive (Yönetimin İşlevleri) adlı kitabı, Frederick Taylor gibi daha önceki yönetim analistlerinin mekanik kavramına karşı çıkmaktadır (Mahoney, 2002; Scott, 1987; Williamson, 1990). Bunun yanı sıra, 1958 yılında California Management Review dergisinde yayımlanan Elementary Conditions of Business Morals isimli makalesi Mckinsey ödülüne layık görülmüştür (Barnard, 1958).

Yöneticinin çağdaş işlevlerini ve rolünü ilk gören yönetim bilimcilerden olan Barnard’ın ortaya attığı fikirlerin yönetim kuramlarının gelişmesine katkısı oldukça belirgindir (Başaran, 1989). Barnard bu düşünceleriyle kendisinden sonra gelen birçok yönetim bilimciyi etkisi altına almıştır (Levitt ve March, 1990). Nitekim ardından gelen Simon'un, Barnard’ın ortaya attığı kısıtlı seçim kavramını sınırlı rasyonellik haline dönüştürerek 1978 yılında Nobel ödülünü alması bunun bir göstergesi olarak değerlendirilebilir. 1961 yılında Barnard'ın ölümü, yönetim alanında önemli bir kayıp olarak görülmüştür. Özetle, Barnard’ın The Functions of the Executive adlı eserinde yer alan fikir ve görüşleri, insan ilişkileri yaklaşımını aşarak, modern yönetim düşüncesine hatta 1970'lerde olgunlaşan sistem yaklaşımına kadar uzanmıştır (Baransel, 1993; Collins ve Porras, 2002). Bu kapsamda, bir yönetim teorisyeni olarak Barnard'ın eğitim yönetiminin bilgi temeli oluşumuna yaptığı katkıların daha iyi anlaşılması için öncelikli olarak yönetim düşüncesi etrafında oluşturduğu konular sırayla sunulmuştur. Daha sonra bu konuların eğitim yönetimine yansımasına ve kavramsal olarak kullanılmasına örnek olacak durumlar ele alınmıştır.

\section{İşbirliği Kuramı}

İşbirliği (cooperation) kuramının sahibi Barnard, doğal örgütün önemine vurgu yapan ve örgütü sosyal bir sistem olarak inceleyen ilk kişidir (Daşlıçay, 1996). Barnard, örgütü “Aralarında sistematik ilişkiler bulunan, fiziksel, biyolojik, psikolojik ve sosyal öğelerden oluşan bir sistem olarak nitelendirmiş ve iki ya da daha fazla bireyin faaliyetlerinin bilinçli olarak koordine edildiği işbirliği sistemi" olarak tanımlamıştır (Barnard, 1958). Buna göre, bir örgütte biçimsel (formal) örgüte dayalı olarak doğal (informal) bir örgüt bulunur (Barutçu ve Haşıloğlu, 2010). Bu doğal örgütün üyeleri arasında astlar kadar üstler de vardır. Biçimsel örgüt bir sistem iken doğal örgüt bilinçsizdir ve düzensiz çalışır. Bu yüzden doğal örgüt biçimsel örgüte zarar verebileceği gibi zaman zaman yararları da dokunabilir (Gross, 1964).

Yöneticilerin yetkilerinin kullanılması sırasında emirden ziyade ikna kabiliyetinin daha etkili olduğunu savunan Barnard, bu noktada iletişimin önemine dikkat çekmiştir (Gabor ve Mahoney, 2010). Eğer örgüt amacına ve emri alanın bedensel ve zihinsel yapısına uygun olan emir, işgören tarafından anlaşılabiliyorsa yetki kabul edilir. Ayrıca Barnard örgütün bir anlam ifade etmesi için insanlar tarafından içinin doldurulması gerektiğini savunmuştur (Kavak ve Vatansever, 2007). Örgütün önem kazanmasının ise ancak işgörenlerin birbirleriyle etkili olarak işbirliği yapması sonucunda gerçekleşeceğini ileri sürmüştür (Peker, 1991).

Barnard'a göre, örgütün varlığını koruması işgörenlerin örgüte katkısı ile örgütün işgörenin ihtiyaçlarını karşılaması arasındaki dengeye bağlıdır. Bu ihtiyaçlar ise maddi, kişisel ve ideal teşvik öğeleri ile karşılanmaktadır (Bursalıoğlu, 2014). Ayrıca örgütlerin bina ve insan gibi somut öğelerin dışında işgörenlerin düşünce ve davranışlarından meydana geldiğini ve bu nedenle de işgörenlerin düşüncelerini dikkate alması gerektiğini vurgulamıştır (Gazell, 1970). Yani Barnard örgütü; fiziki, biyolojik, kişisel ve toplumsal öğelerden oluşan bir işbirliği sistemi olarak nitelendirmiştir (Barnard, 1976). Biçimsel yapı ve kontrollerin, işbirliği sistemlerinin temel doğasını tanımlamakta yetersiz kaldığını gören Barnard, kullandığı gönüllülük kavramını işbirliği sistemleri için vazgeçilmez bir unsur olarak kabul etmiştir. Ona göre, insanların gönüllü çabalarıyla katkı sağlamaları işbirliği sistemleri ya da örgütler için yaşamsal öneme sahiptir. Dolayısıyla örgütlü faaliyetlerin tümünde işbirliği için gönüllülük esastır (Akbaş, 2011).

Barnard, stratejik yönetim alanında daha dinamik modeller için işbirliği, amaç ve iletişim olmak üzere üç temel ilkeden bahsetmiştir (McMahon ve Carr, 1999). Bu ilkeler aynı zamanda bir örgütün ortaya çıkabilmesi için zorunlu olan ortak amaç, iletişim ve çalışanların işbirliği arzusu adlı üç öğenin temelini oluşturmaktadır (Bursalıŏ̆lu, 2014). Barnard, örgütleri insan faaliyetlerinin 
işbirliği yaptığı sistemler olarak ele almış ve bu sistemlerin genel olarak kısa ömürlü olduğunu vurgulamıştır (Arslan, 2010). Barnard'a göre örgütlerin uzun ömürlü olamamalarının sebebi, yaşamak için gerekli olan etkililik ve verimlilik ölçütlerini karşılayamamalarıdır. Barnard etkililik kavramını "Belirlenen amaçları gerçekleştirebilmek" şeklinde bilinen bir ifadeyle tanımlamaktadır. Ancak verimlilik kavramını bilinen tanımlardan farklı olarak "Bir örgütün verimliliği, üyelerinin motivasyonlarını sağlayabilme derecesi" olarak ifade etmiştir. Ona göre, eğer bir örgüt tanımlanmış amaçlarına ulaşırken üyelerini motive edebilir ve üyeler arasında işbirliğini sağlayabilirse örgüt yaşamaya devam edecektir (Arslan, 2010; Wren ve Bedeian, 2009). Bahsedilen bu görüşlerden yola çıkarak oluşturulmuş Barnard'a ait örgüt vizyonu çerçevesi Şekil 1'de sunulmuştur.

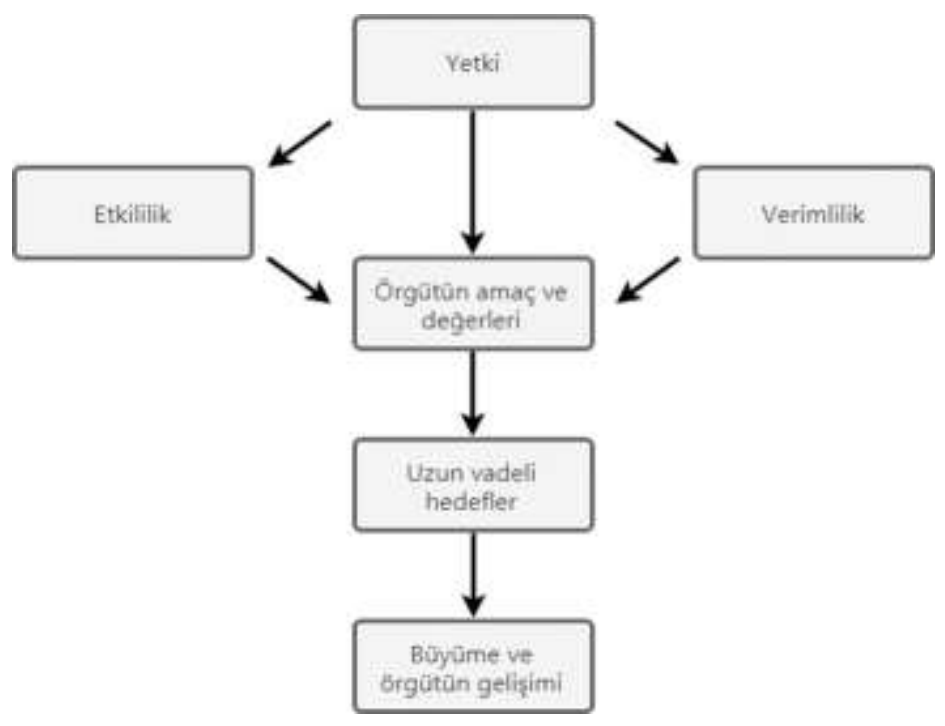

\section{Şekil 1. Barnard'ın Örgüt Vizyonu (Nikezić vd., 2016, s. 130)}

Barnard The Functions of the Executive adlı eserinde ilk defa işbirliği sistemini "En az bir kesin sonuca ulaşmak için iki ya da daha fazla kişinin işbirliğiyle bir araya gelerek oluşturduğu belirli bir sistematik ilişki içinde olan fiziksel, biyolojik, kişisel ve sosyal alanları olan bileşik" şeklinde tanımlamıştır (Barnard, 1976, s. 88). Burada önemli olan nokta, kişiler arasındaki ortak bir davranış sergileyebilme, birlikte hareket edebilme ve bilgiyi paylaşabilme duygularının gönüllü olarak ortaya çıkmış olmasıdır (Sağsan, 2006). Gatewood'a (1995) göre bireylerin tek başlarına gerçekleştiremeyecekleri hedefleri, örgütler aracıllğıyla yine kendi yetenekleri ile yapabilmeleri üzerine savunmaların en iyisi Barnard tarafından yapılmıştır.

Birey üzerine yönelen Barnard, bireyin sahip olmadığı yeteneğin istediği şeyi yapmasına engel bir durum olarak ifade etmektedir. Barnard, bireyin yeteneksizliklerini iki gruba ayırarak, bireyin biyolojik kapasitesi ve bireyin karşılaştığı çevrenin fiziksel faktörleri olarak sınıflandırmaktadır (Gehani, 2002). Bu açıkladığı sınıflandırmada Barnard özellikle iki konu üzerinde durmaktadır. Bunlardan ilki, bireyin sahip olduğu yeteneklerin birbirleriyle doğrudan ilişki içinde bulunduğuna ilişkindir. İkincisi ise birey ne yapmak istiyorsa bunu açık bir şekilde ortaya koyması gerekliliğidir. Eğer, bireyin belirli veya özel bir amacı yoksa bu yetenek sözcüğünün fazla bir anlamı kalmayacaktır (Şimşek ve Çelik, 2018). Çünkü bireyin sahip olduğu ya da olmadığı bir yetenek belirli veya özel amaca hizmet etmemiş olacaktır. Barnard'a göre ilk insanlar güçlerini birleştirmekle bireysel güçlerinin arttığını fark etmiştir. Bu nedenle, daha sonra bilinçli ve gönüllü olarak organize olmaya başlamışlardır. Böylece birey, örgüt aracılığıyla kendisinde var olmayan ya da eksik olan yetenekleri yenerek veya ortadan kaldırarak, kendi amaçlarına ulaşmayı başarmıştır (Barnard, 1958).

Astlar içinde çalıştıkları örgütün amaçları, çalışma usulleri ve bunlarda meydana gelecek değişiklikler hakkında bilinçli veya bilinçsiz olarak bilgi sahibi olmayı isterler (Eren, 2017). Bununla birlikte, örgüt üyelerinin birbirleriyle karşılıklı işbirliğine girmeleri de bilgi paylaşımı ile gerçekleşir. Bu nedenle örgüt içerisinde kurulacak olan iyi bir işbirliği ile bu bilgi paylaşımı etkili bir şekilde gerçekleşecektir. Nitekim Barnard'a göre işbirliği ancak birbiriyle iletişim kuran katılımcılar tarafından gerçekleştirilebilir. Bu noktada, yöneticiye iletişim sistemini kurma görevi düşmektedir (Başaran, 1989). Örgüt içinde kurulan iletişim beraberinde daha etkin problem çözümünü ve daha yüksek verimliliği getirecektir. Özetle, Barnard örgüt içerisinde çalışan bütün üyeleri örgütsel faaliyetlerle ilgili işbirliği çalışmalarının bir parçası olarak görmekte ve bilgi paylaşımını desteklemektedir.

Sonuç olarak Barnard, örgütü fiziki, biyolojik, kişisel ve toplumsal öğelerden oluşan bir sistem olarak nitelendirmiştir. Şüphesiz örgütü bir araya gelen parçalardan daha büyük bir sistem olarak tanımlaması onu klasik kuramcılardan ayıran özelliklerden birisidir. Hatta bu düşünce yapısı onu sistem düşünürleri arasına dahil etmiştir. Barnard'ın bireyleri, örgütleri, satıcıları ve alıcıları bir çevrenin parçaları olarak görmesi, bahsedilen sistem düşünce yapısına örnek teşkil etmektedir. Dolayısıyla Barnard’ın ortaya koyduğu eserler, klasik kuram ile davranışsal kuram arasında bir köprü görevi görmüştür (Öğüt ve Öztürk, 2007). Doğal sistem görüşü içerisinde yer alan Barnard'ın işbirlikçi sistem yaklaşımı, örgütte çalışan bütün üyeleri işbirliği çalışmalarının bir parçası olarak görmektedir (Peker, 1991; Sağsan, 2006). Bu durumda örgüt içerisindeki eylemleri sınırlayan bireysel yetenek eksikliğine karşı örgütün gelişimini ve devamını sağlamaktadır (Kavak ve Vatansever, 2007; Şimşek ve Çelik, 2018). 


\section{Kayıtsızık Alanı}

Barnard'ın geliştirdiği kayıtsızıı alanı kuramına kadar geçen süreç içerisinde yetki kavramı üzerinde çeşitli görüşler ortaya atılmıştır. Bunlardan ilki yetkinin üstten asta doğru akışıdır. Bu yetki akışının çıkış noktası askeri sistemdir (Gazell, 1970). Buna göre, yetki kavramı "Yöneticinin emir verme hakkı" olarak tanımlanmış ve bu anlayış 20. yüzyılın başına değin devam etmiştir. 1930'larda mevcut yönetim teorisine yapılan eleştirilerin bir sonucu olarak, insan ve insan ilişkilerinin belirgin hale geldiği bir süreç başlamıştır. Bu noktada yetkiyi kabul edilmiş bir mesaj olarak tanımlayan Barnard, üstlerin bu mesajı yetki olarak tanımlamaları için dört şartın yerine getirilmesi gerektiğini belirtmektedir. Bunlar; ast tarafından anlaşılabilir olması, örgütün amaçlarına uygun olması, astın çıkarlarıyla çelişmemesi ve astın bu emri yerine getirme gücüne sahip olmasıdır (Gazell, 1970).

Yekti kavramından yola çıkarak Barnard, daha sonra Simon tarafından kabul alanı olarak yeniden ifade edilecek olan kayıtsızlık alanı diye bir alanın varlığından bahsetmiştir (Özalp, Şahin, Berberoğlu ve Geylan, 2004). Barnard'a göre yetki ast ve üst arasında otoriter bir iletişim niteliği taşımaktadır. Yöneticilerin emir verme yetkisiyle donatılmaları, astların yöneticilere itaat etmesinde yeterli olmamaktadır. Yani yetki veya emir verme hakkı, astların uyup uymamasına bağlıdır. Doğal olarak işgören, yönetici tarafından belirlenecek bir sonucu kabul etmede istekli olabilir ancak bu durum emirlerin zorunlu olarak kabul edilmesini güvence altına almaz (Ögüt ve Öztürk, 2007). Çünkü astların emirleri kabul etmelerinin de bir sınırı vardır (Başaran, 1989). Barnard bu durumu "Bir örgütteki işgörenlerin, yöneticiden gelen emirleri veya yöneticilerin aldıkları kararları isteyerek uygulamaya aktarmaları" şeklinde tanımladığı kayıtsızlık alanı kavramıyla açıklamaktadır. Dolayısıyla bir yöneticinin başarılı olabilmesi için öncelikle tüm çalışanlarının kayıtsızlık alanını genişletmesi gerektiğini vurgulamıştır (Öğüt ve Öztürk, 2007). Ancak yetkinin bir dereceye kadar kabulünü zorunlu sayan kayıtsızlık alanı kavramı, yararlı bir genelleme olmakla beraber, yetkinin kabulünü kolaylaştıran sosyal ve psikolojik etkenlerden bir kısmını ihmal etmiştir (Bursalıoğlu, 2014).

\section{Karar Kuramına Katkısı}

Karar verme kuramının öncüsü olan Barnard, örgütü bir karar verme süreci olarak nitelendirmektedir (Başaran, 1989). Ona göre karar verme, stratejik etmenlerin aranmasıdır. Stratejik etmen ise tam zamanında ve doğru olarak denetlendiğinde amaca uygun koşullar yaratan ya da sistemin istenilen yönde değişmesine yol açan etmendir. Sözgelimi, tahıl üretimi için bir toprağın verimini artırmak isteniyorsa ve araştırmada toprakta potasyum miktarının az olduğu görülmüşse o halde potasyum stratejik bir etmen olacaktır (Onaran, 1975). Bunların yanı sıra Barnard, kendinden önceki kuramcılardan farklı olarak insanın karar verme süreçlerindeki sınırlılıklarına vurgu yapmıştır. Kişilerin çözümler arasından seçim yaparken dikkatini sınırlayıcı yani stratejik etkenler üzerine çevirmesi gerektiğini ifade etmiştir (Bursalıoğlu, 2013).

Barnard'a göre yönetim kararları ahlaki sorunlarla bir ilişki içerisindedir (Bursalıoğlu, 2014). Kişi karar alırken fiziksel, biyolojik ve toplumsal faktörlerden etkilenir. Bu nedenden ötürü alınacak kararların her zaman rasyonel olması düşünülemez. Çünkü bütün karar öğeleri, yani bütün alternatifler, sonuçlar ve bu sonuçlara verilen değerler bu tanımda yer alamayacaktır. Bir kez karar veren, bir durumdaki bütün alternatifleri ve bunların ne gibi sonuçlar doğuracağını tam olarak kestiremez. Barnard, tüm bu karar verme süreçlerindeki sınırlılıkları kısıtlı seçim kavramıyla kuramsallaştırmıştır. Daha sonra Simon bu kavramı geliştirerek sınırlı rasyonellik kavramını ortaya atmıştır (Onaran, 1975). Sonuç olarak Barnard, bireysel kısıtlamaların doğru karar almaya engel olduğunu ve dolayısıyla bireyin bu kısıtlı kapasitesinin örgüt içerisindeki işbirliği uygulaması ile genişletilebileceğini savunmaktadır (Öğüt ve Öztürk, 2007).

\section{Yönetimin Bilgi Temeli Oluşumuna Katkısı}

Çalışmalarında sorumluluk, kayıtsızlık alanı, işbirliği, amaçlar, iletişim, örgüt, karar verme gibi konulara ağırlık veren Barnard, klasik yönetim kuramcılarının özellikle Henri Fayol ve Frederick Taylor’un görüşlerini geliştirmiştir (McMahon ve Carr, 1999). İşgörenler arasındaki iletişime dikkat çekerek birbirleri arasındaki iletişimin nasıl olması gerektiğini sosyolojik ve psikolojik yönleriyle açıklamıştır. Bu sayede, farklı bilim alanlarını yönetim sürecine dahil ederek yönetim kuram ve uygulamasında yeni bir bakış açısı geliştirmiş ve yönetim alanında daha önce etkisi ortaya konulmayan noktalara değinmiştir (Mahoney, 2002). Barnard, her ne kadar yönetim alanında ortaya koyduğu iki eserinde yer alan fikirleri çok açık şekilde ifade etmemiş olsa da onları derinlemesine açıklamayı başarmıştır (Bursalıoğlu, 2014).

Barnard'ın çalışmaları bir noktada klasik yönetim teorilerine eleştiri niteliği taşımaktadır (Sucu, 2000). Çünkü, Barnard şirket yöneticiliği döneminde elde ettiği deneyimlerinin hiçbirinin o güne kadar yazılmış olan eserlerle uyuşmadığını fark etmiştir. Bu nedenle de eserini eleştirel bir üslupla kaleme alarak, örgütleri biçimsel yapıları yerine davranışsal boyutları açısından analiz etmiştir (Sağsan, 2006). Barnard kuramında insan öğesi üzerinde durarak, onu kuramının içerisine sistematik bir şekilde yerleştirmiştir. Barnard'ın yönetim bilimine en önemli katkısı kendisinden önce gelen yönetim kuramcılarından farklı bir yönetici fonksiyonu formüle etmiş olmasıdır (McMahon ve Carr, 1999; Öğüt ve Öztürk, 2007). Barnard (1976), günlük hayatta elde ettiği pratik deneyimlerini kullanarak oluşturduğu, üst düzey yöneticilerin fonksiyonlarını şu şekilde açıklamıştır:

1. Üst Düzey Yöneticilerin Birinci Fonksiyonu: Yönetici tarafından iletişim sisteminin kurulup devamlılığının sağlanmasıdır. Bu fonksiyon kendi altında iki alt fonksiyonlara ayrılmıştır. Bunlardan ilki; personelin seçimi, güdülenmesi, olumlu ve olumsuz yaptırımlar, yükseltme ve işten çıkartma gibi biçimsel örgütün meydana getirilmesidir. İkincisi ise personelin moralini ve örgüte bağlılığını yüksek düzeyde tutmayı sağlayacak olan, biçimsel olmayan süreçlerin desteklenmesidir. 
2. Üst Düzey Yöneticilerin İkinci Fonksiyonu: İşgörenlerin istihdam edilmesi ve işgörenlerden maksimum faydayı sağlayabilmek için önlemler alınmasını içermektedir. Bu fonksiyon özellikle işgörenlerin terfi ettirilmesini ve diğer motivasyon çalışmalarını öne çıkarmaktadır.

3. Üst Düzey Yöneticilerin Üçüncü Fonksiyonu: Örgütün amaç ve hedeflerinin belirlenmesidir. Bu nedenle, genel planların hazırlanması ve bu planlar uyarınca gerekli işgörenlerin görevlendirilmesi bu fonksiyon açısından önem taşımaktadır.

\section{Eğitim Yönetiminin Bilgi Temeli Oluşumuna Katkısı}

20. yüzyılın başına kadar daha çok felsefi tartışmalardan beslenen eğitim yönetimi alanı o dönemde henüz bilimsel bir niteliğe kavuşamamıştır (Heck ve Hallinger, 2005). 20. yüzyılın ilk çeyreğinde ise Taylor tarafından ortaya atılan bilimsel yönetim, işletme ve ekonomi alanlarına bağımlı olarak gelişim göstermiştir. Bu dönemdeki verimlilik arayışları, sonraki yıllarda eğitim yönetiminin kurumsallaşmasında ve akademik bir disiplin haline gelmesinde önemli rol oynamıştır (Oplatka, 2016). Bununla birlikte, Amerikan eğitim sistemine hakim olan işletme tabanlı yönetim yaklaşımı, eğitim yönetiminde eğitim ideallerini arka planda tutmaya yönlendirmiştir (Bates, 2010). ABD'de 1930'lu yıllarda demokratik yönetim yaklaşımına olan ilginin artması ve insan ilişkilerinin yönetimdeki önemi ampirik çalışmaların desteklenmesine yol açmıştır (O'Connor, 1999). Bu noktada, Barnard'ın The Functions of the Executive adlı kitabında yer verdiği karar, yetkinlik, ahlaki bütünlük, akılcı yönetim, profesyonellik, sistem yaklaşımı ve işbirliği hakkındaki görüşleri eğitim yönetimi alanında derin etkiler bırakmıştır (Gabor ve Mahoney, 2010). Nitekim bu etkiler, eğitim yönetimi alanının bağımsız ve kendine özgü bir kimlik yaratma çabası içine girmesini amaçlayan bir hareket başlatmıştır. Daha sonra teori hareketi olarak adlandırılan bu dönemde eğitim yönetimi; kuram ve uygulama boyutu doğrudan ilişkili olan ancak kuramın uygulamayı belirlediği bir dönüşüm yaşamıştır (Balcı, 2008; Oplatka, 2009; Sergiovanni, 2009).

Barnard'ın yönetim alanında verimlilik söylemlerine karşı ortaya koyduğu insan ilişkileri yaklaşımı 1940’lı yıllardan sonra eğitim yönetimi alanında çeşitli araştırmacılar tarafından yazılan eserlerde kendini göstermektedir. Örneğin; Griffiths (1956) Human Relations in School Administration kitabında, eğitim yönetimi alanında yapılan araştırmaların kuramlara dayandırılmasını ve sosyal bilimcilerin eğitim yönetimi alanındaki araştırmacılara kuramların kullanımı noktasında rehberlik yapmaları gerektiğini belirtmiştir. Benzer şekilde, Mort ve Ross (1957) Principles of School Administration başlıklı çalışmasıyla okul yönetiminde insan odaklı yaklaşımın önemine dikkat çekmişlerdir (Özdemir, 2019). Bridges $(1964,1967)$ ile Kunz ve Hoy $(1976)$ ise Barnard'ın ortaya attı̆̆ı kayıtsızlık alanı kavramını eğitim örgütleri bağlamında yeniden ele almışlardır. Sonuç olarak, Barnard tarafından yönetim alanında ortaya atılan pek çok kavram ve yaklaşım eğitim yönetimi alanındaki öncü araştırmacıları ve çalışma konularını doğrudan etkilemiştir. Bu noktada, Barnard'ın eğitim yönetimini hangi kavramlar üzerinden etkilediğini ve bu kavramların alanda nasıl karşılık bulduğunu göstermek için aşağıda bazı somut örneklere yer verilmiştir.

1. Bilgi Paylaşımı: Her eğitim-öğretim yılının ilk ayında toplanan şube öğretmenler ve zümre öğretmenler toplantısında bir araya gelen öğretmenler hem branş dersleri hem de öğrenciler hakkındaki görüş ve izlenimlerini birbirleriyle paylaşırlar. Bu durum Barnard'ın işbirliği teorisindeki bilgi paylaşımı durumunu içermektedir.

2. Doğal ve Biçimsel Örgüt: Bir okulda aynı branşta görev yapan iki öğretmenin zümre toplantılarında kurduğu ilişki biçimsel bir örgüt yapısı iken bu iki öğretmenin öğlen yemeğini beraber yemeleri, birlikte spora gitmeleri doğal örgüt yapısıdır.

3. Etkililik: Okul yönetimi tarafından okula yeni başlayacak tüm öğrencilerin yıl sonuna kadar okuma-yazma öğretimine hazır hale gelmesinin bir hedef olarak verilmesi ve bu hedefin belirlenen sürede gerçekleşmiş olması eğitim örgütlerinde etkililik kavramını açıklamaktadır.

4. Gönüllülük: Öğretmenlerin projelere ve ders dışı etkinliklere kendi istekleriyle gönüllü olarak katılmaları Barnard’ın işbirliği sistemi içerisinde vazgeçilmez olan gönüllülük durumunu göstermektedir.

5. Karar Verme: Okul terk oranlarının yüksek olduğu bir okul ya da bölgede öğrencilerin okul terk nedenlerinin tespit edilerek, buna yönelik aksiyon planları hazırlanması Barnard'ın stratejik etmenlerin aranması olarak ifade ettiği karar verme kavramını temsil etmektedir.

6. Kayıtsızlık Alanı: Okul müdürünün ders dışı etkinlikler ile ilgili aldığı kararın öğretmenler tarafından kabul edilmesi, bu kararın Barnard'ın bir örgütteki işgörenlerin, yöneticiden gelen emirleri veya yöneticilerin aldıkları kararları isteyerek uygulamaya aktardıkları alan olarak nitelendirdiği kayıtsızlık alanı içinde olduğunu göstermektedir.

7. Sorumluluk: Okul yöneticisinin okula giriş ve çıkış saatine dikkat etmesi aynı zamanda kılık ve kıyafetine özen göstermesi, okuldaki diğer yöneticileri, öğretmenleri ve öğrencileri bu vasıtayla etkilemesi Barnard'a göre, yöneticinin örnek olma davranışı demek olan sorumluluk kavramına örnektir.

8. Verimlilik: Her eğitim-öğretim yılı başında yapılan öğretmenler kurul toplantısında öğretmen görüşlerini alan ve karar aşamasına bu görüşleri dahil eden okul yöneticisinin bu vasıtayla öğretmenleri motive etmiş olması verimlilik ya da başka bir deyişle verimliliği artırıcı bir unsur olarak ele alınmaktadır.

9. Yetki: Okul yöneticilerinin emrine rağmen birçok öğretmen okullarda ders aralarında tutulan nöbetin ücrete tabi tutulmamasından ve sorumluluk yükünün fazla olmasından dolayı yerine getirmemektedir. Barnard verilen emrin yerine getirilmesi için hem kişisel beklentilere hem de örgütün amaçlarına uygun olması gerektiğini ifade etmiş ve emrin yetkiye ancak bu şekilde dönüşebileceğini savunmuştur. Dolayısıyla burada kişisel beklenti ve çıkarlara uygun düşmeyen nöbet tutma emri yetkiye dönüşememektedir.

| Kastamonu Eğitim Dergisi, 2020, Vol. 28, No. 31 


\section{SONUÇ VE TARTIŞMA}

Yönetim alanındaki gelişmelere paralel olarak 20. yüzyılın ilk çeyreğinde ayrı bir disiplin olarak ortaya çıkan eğitim yönetimi alanı, bu dönemden itibaren kendi sınırlarını ve özgün kimliğini oluşturma gayreti içerisinde olmuştur (Özdemir, 2017). Bu inşa sürecinde üç etmen önemli bir rol oynamıştır. Bunlardan ilki, bir bilim olma yolunda önemli aşama kaydeden eğitimin kendisidir. İkincisi, 1929 yılında yaşanan buhrana kadar olan süreçteki verimlilik arayışlarıdır. Üçüncüsü ise eğitim yönetiminin bilimleşme sürecinde görülen yönetim biliminin etkisidir (Özdemir, 2018). Bu dönemde eğitim yönetimi, yönetim biliminden devşirdiği teori ve kavramları kendine uyarlama çabası işine girişerek kamu ve işletme yönetimi bilimleri arasında sıkışmış bir imaj vermiştir (Evers ve Lakomski, 2015; Greenfield, 1986; Özdemir, 2011). Klasik yönetim anlayışında insan ve insan ilişkilerinin göz ardı edilmesi eğitim örgütlerinin sadece verimlilik anlayışıyla çalışan bir örgüt olarak görülmesine sebep olmuştur. Ancak Hawthorne araştırmalarının işletme örgütlerinde dahi durumun sadece yapıdan ibaret olmadığını göstermesi örgütler için yeni bir hareketi doğurmuştur. Bunun ardından, Barnard'ın yönetim alanında temsil ettiği insan ilişkileri yaklaşımında öne çıkan motivasyon, yetki, liderlik, sosyal sorumluluk, etik gibi kavramlar kısa sürede eğitim yönetimi literatürüne girmiştir.

Barnard’ın önderliğini yaptığı yönetim biliminde insan ilişkileri ekolü, izleyen yıllarda eğitim yönetimi alanını derin şekilde etkisi altına almıştır (Özdemir, 2017). Bunun en önemli nedenlerinden biri, insan ilişkileri ekolünün Taylor ve Fayol'un temsil ettiği klasik yönetim anlayışının aksine yönetimde informal yapıyı ve dolayısıyla insan ilişkilerini tanımasıdır. Bu gelişmelere bağlı olarak, eğitim yönetimi alanı 1940 ve 1950'lerde kuramsal yapıya odaklanmış ve bu nedenle de rasyonel bilimsel yöntemini kucaklamıştır. Sonunda her okul yöneticisinin, yönetim bilimine ve yönetim kuramına dayanması gerektiği düşünülmüş ve takip eden yıllarda sosyal ve davranış bilimleri tarafından etkilenen kurama dayalı araştırma anlayışı eğitim programlarında değişime neden olmuştur (Berry ve Beach, 2009). Bu durum ise eğitim yönetimi alanında teknik bir bakış açısının ön plana çıktığı teori hareketinin oluşumunu tetiklemiştir (Brundrett, 2001).

Eğitim örgütlerinin odağı, doğası gereği insan ve insan davranışı üzerinedir. Dolayısıyla eğitim örgütlerinin başarısının çok gruplu, çok değişkenli ve çevrenin etkilerine açık konumda bulunan yapısını, işbirliği ilkeleri doğrultusunda iç ve dış dinamiklere uyarlamasına bağlı olduğu ifade edilebilir. Bu doğrultuda, eğitim örgütünün örgütsel, yönetsel ve eğitsel hedeflerinin gerçekleştirilmesi büyük ölçüde iç ve dış dinamikler arasındaki işbirliğine ve etkileşime bağlıdır. Barnard'ın örgütlerde amaçlara ulaşma ve üye ihtiyaçlarını karşılama konusundaki görüşleri ve yöneticinin bunu sağlamak için otorite ve yetki kullanımını değerlendirmesi eğitim örgütleri açısından oldukça uygun yapıdadır (Elma, 2018; Hoy ve Miskel, 2015). Bu görüşe göre, okul yöneticisi otorite yerine etkileme yöntemlerini kullanarak etrafındaki kişilerle daha etkili bir etkileşim ağı kuracaktır (Bursalıoğlu, 2014). Özellikle 1980 'li yılların ardından bir ivme kazanan ve günümüzde de eğitim alanında güncelliğini koruyan liderlik teması bu savı destekler niteliktedir. Bahsedilen tüm bu gelişmeler, Taylor'ın bilimsel yönetim okulunun ve Elton Mayo'nun insan ilişkileri yaklaşımının basit ve pragmatik bir sentezini geliştiren Barnard'ın eğitim yönetiminin bilimleşme sürecindeki seyrini nasıl etkilediğini ortaya koymaktadır.

\section{Teşekkür}

Bu çalışmanın olgunlaştırımasına değerli görüş, öneri ve desteği ile katkı sunan Prof. Dr. Murat Özdemir'e en içten teşekkürlerimi sunarım.

\section{KAYNAKÇA}

Akat İ. ve Budak G. (2002). İşletme yönetimi. İzmir: Barış Yayınları.

Akbaş, T. T. (2011). Algılanan kişi-örgüt uyumunun örgütsel vatandaşlık davranışları üzerindeki etkisi: Görgül bir araştırma. Yönetim Bilimleri Dergisi, 9(1), 57-81.

Aktan, S. (2015). John Franklin Bobbitt'te program düşüncesinin gelişimi: Tarihsel bir inceleme. Electronic Turkish Studies, 10(15), 35-50.

Arslan, A. (2010). Katılımlı yönetim tekniği arama konferansı uygulamalarının kurumsal performansa etkisi. Sakarya Üniversitesi Fen Edebiyat Dergisi, 12(1), 117-142.

Balcı, A. (2008). Türkiye'de eğitim yönetiminin bilimleşme düzeyi. Kuram ve Uygulamada Egitim Yönetimi Dergisi, 14(2), $181-209$.

Baransel, A. (1993). Çağdaş yönetim düşüncesinin evrimi. İstanbul: Avcıol Basım Yayım.

Barnard, C. I. (1958). Elementary conditions of business morals. California Management Review, 1(1), 1-13.

Barnard, C. I. (1976). The functions of the executive. London: Harvard University Press.

Barutçu, E. ve Haşıloğlu, S. B. (2010). Organizasyonlarda internetin informal ve viral iletişim aracı olarak kullanımı. Internet Uygulamaları ve Yönetimi Dergisi, 1(2), 5-16.

Başaran, i. E. (1989). Yönetim. Ankara: Gül Yayınevi.

Bates, R. J. 2010. History of educational leadership and management. P. Peterson, E. Baker ve B. McGraw (Ed.), International encyclopedia of education içinde (ss. 724-730). Oxford: Elsevier.

Berry, J. ve Beach, R. (2009). K-12 leadership and the educational administration curriculum: A theory of preparation. National Council of Professors of Educational Administration. 15 Eylül 2019 tarihinde http://cnx.org/content/m13772/latest/ adresinden erişildi.

Beycioğlu, K. ve Dönmez, B. (2006). Eğitim yönetiminde kuramsal bilginin üretimine ve uygulanmasına ilişkin bir değerlendirme. Kuram ve Uygulamada Egitim Yönetimi Dergisi, 12(3), 317-342. 
Bridges, E. M. (1964). Teacher participation in decision making. Administrator's Notebook, 12, 1- 4.

Bridges, E. M. (1967). A model for shared decision making in the school principalship. Educational Administration Quarterly, 3(1), 49-61.

Brundrett, M. (2001). The development of school leadership preparation programmes in England and the USA: A comparative analysis. Educational Management \& Administration, 29(2), 229-245.

Bursalıoğlu, Z. (2013). Okul yönetiminde yeni yapı ve davranış. Ankara: Pegem Akademi.

Bursalığlu, Z. (2014). Eğitim yönetiminde teori ve uygulama. Ankara: Pegem Akademi.

Çalık, T. (1997). Etkili eğitim yöneticisi. Millî Eğitim Dergisi, 135, 55-58.

Chandran, J. (2010). The relevance of Chester Barnard for today's manager. 5 Mart 2019 tarihinde http://citeseerx.ist.psu.edu/viewdoc/download?doi=10.1.1.554.7612\&rep=rep1\&type=pdf adresinden erişildi.

Collins, J. C. ve Porras, J. I. (2002). Built to last: Successful habits of visionary people. New York, NY: Harper Business Essentials.

Dalay, i. (2001). Yönetim ve organizasyon. Adapazarı: Sakarya Üniversitesi Yayınları.

Daşlıçay, N. (1996). Örgüt ve yönetim kuramları. 23 Mart 2018 tarihinde https://docplayer.biz.tr/2609287-Orgut-ve-yonetim-kuramlari.html adresinden erişildi.

Eacott, S. (2015). Educational leadership relationally: A theory and methodology for educational leadership, management and administration. Rotterdam: Sense Publishers.

Eacott, S. ve Evers, C. (2015). New Frontiers in Educational Leadership. Management and Administration Theory, 47(4), 307-311.

Elma, C. (2018). Neoklasik yönetim kuramları. K. Demir ve K. Yılmaz (Ed.), Yönetim ve eğitim yönetimi kuramları içinde (ss. 41-66). Ankara: Pegem Akademi.

English, F. W. (2002). The point of scientificity, the fall of the epistemological dominos, and the end of the field of educational administration. Studies in Philosophy and Education, 21(2), 109-136.

English, F. W. (2006). The unintended consequences of a standardized knowledge base in advancing educational leadership preparation. Educational Administration Quarterly, 42(3), 461-472.

Eren, E. (2017). Örgütsel davranış ve yönetim psikolojisi. İstanbul: Beta Yayıncılık.

Ertürk M. (2018). İşletmelerde yönetim ve organizasyon. İstanbul: Beta Basım Yayım.

Evers, C. W. ve Lakomski, G. (2015). Naturalism and educational administration: New directions. Educational Philosophy and Theory, 47(4), 402419.

Gabor, A. ve Mahoney, J. T. (2010). Chester Barnard and the systems approach to nurturing organizations. M. Witzel (Ed.), Oxford handbook of management theorists içinde (ss. 134-151). Oxford: Oxford University Press.

Gatewood, G. D. (1995). A study of the astrometric motion of Barnard's star. Astrophysics and Space Science, 223(1-2), 91-98.

Gazell, J. A. (1970). Authority-flow theory and the impact of Chester Barnard. California Management Review, 13(1), 68-74.

Gehani, R. R. (2002). Chester Barnard's “executive" and the knowledge-based firm. Management Decision, 40(10), 980-991.

Greenfield, T. B. (1986). The decline and fall of science in educational administration. Interchange, 17(2), 57-80.

Griffiths, D. E. (1956). Human relations in school administration. New York, NY: Appleton-Century-Crofts.

Gross, B. M. (1964). The managing of organizations: The administrative struggle. New York, NY: Free Press of Glencoe.

Heck, R. H. ve Hallinger, P. (2005). The study of educational leadership and management: Where does the field stand today?. Educational Management Administration \& Leadership, 33(2), 229-244.

Hitt, M. A., Black, J. S. ve Porter, L. W. (2011). Management. New York, NY: Pearson.

Hoy, W. K. ve Miskel, C. (2015). Eğitim yönetimi: Teori, araştırma ve uygulama. S. Turan (Çev. Ed.). Ankara: Nobel Yayınevi.

Kavak, B. ve Vatansever, N. (2007). Hizmet sektöründe örgüt içi iletişim bileşenleri ve işgören verimliliği üzerindeki etkileri: Ankara'daki beş yıldızlı otel işgörenlerinin düşünceleri. Ticaret ve Turizm Eğitim Fakültesi Dergisi, 2(2), 120-140.

Koçel, T. (2018). İ̧̧letme yöneticiliği. İstanbul: Beta Basım Yayın.

Kunz, D. W. ve Hoy, W. K. (1976). Leadership style of principals and the professional zone of acceptance of teachers. Educational Administration Quarterly, 12(3), 49-64.

Levitt, B. ve March, J. G. (1990). Chester I. Barnard and the intelligence of learning. D. Williamson (Ed.), Organization theory: From Chester Barnard to the present and beyond içinde (ss. 11-37). Oxford: University Press.

Lunenburg, F. C. ve Ornstein, A. C. (2012). Educational administration: Concepts and practices. California, CA: Wadsworth Cengage Learning.

Mahoney, J. T. (2002). The relevance of Chester I. Barnard's teachings to contemporary management education: communicating the aesthetics of management. International Journal Organization Theory and Behavior, 5(1-2), 159-172.

McMahon, D. ve Carr, J. C. (1999). The contributions of Chester Barnard to strategic management theory. Journal of Management History, 5(5), 228-240.

Memduhoğlu, H. B. ve Yılmaz, K. (2013). Yönetimde yeni yaklaşımlar. Ankara: Pegem Akademi.

Mort, P. R. ve Ross, D. H. (1957). Principles of school administration. New York: McGraw-Hill.

Nikezić, S., Dželetović, M. ve Vučinić, D. (2016). Chester Barnard: Organisational-management code for the 21st century. Procedia-Social and Behavioral Sciences, 221, 126-134.

O'Connor, E. S. (1999). Minding the Workers: The Meaning of 'Human' and 'Human Relations' in Elton Mayo. Organization, 6(2), $223-246$. 
O'Connor, E. S. (2012). Creating new knowledge in management: Appropriating the field's lost foundations. Stanford, CA: Stanford University Press.

O'Connor, E.S. (2013). New contributions from old sources: Recovering Barnard's science and revitalizing the Carnegie School. European Management Journal, 31, 93-103.

Öğüt, A. T. ve Öztürk, Y. E. (2007). Yönetimin bilimleşme (scientization) sürecine katkıları açısından Barnard ve Herbert Alexander Simon betimleyici ve ilişkilendirici bir çalışma. Selçuk Üniversitesi Sosyal ve Ekonomik Araştırmalar Dergisi, 1(14), 29-46.

Onaran, O. (1975). Örgütlerde karar verme. Ankara: Sevinç Matbaası.

Oplatka, I. (2009). The field of educational administration: A historical overview of scholarly attempts to recognize epistemological identities, meanings and boundaries from the 1960s onwards. Journal of Educational Administration, 47(1), 8-35.

Oplatka, I. (2016). Eğitim yönetiminin mirası: Akademik bir alanın tarihi analizi. S. Turan, F. Bektaş ve M. Yalçın (Çev.). Ankara: Pegem Akademi.

Özalp, I., Şahin, M., Berberoğlu, G. ve Geylan, R. (2004). Yönetim organizasyon. C. Koparal (Ed.). Eskişehir: Anadolu Üniversitesi Yayınları.

Özdemir, M. (2011). Kamu yönetimi ve işletme yönetimi arakesitinde bir bilim: Eğitim yönetimi. Amme Idaresi Dergisi, 44(2), $29-42$.

Özdemir, M. (2017). Eğitim yönetiminde epistemik bunalımın arkeolojisi. Kuram ve Uygulamada Eğitim Yönetimi Dergisi, 23(2), 281-304.

Özdemir, M. (2018). Eğitim yönetimi: Alanın temelleri ve çağdaş yönelimler. Ankara: Anı Yayıncılık.

Özdemir, M. (2019). Eğitim yönetiminin tarihsel temelleri. N. Cemaloğlu ve M. Özdemir (Ed.), Eğitim yönetimi içinde (ss. 17-32). Ankara: Pegem Akademi.

Peker, Ö. (1991). Yetkinin göçerilmesi ve kullanımı. Amme Idaresi Dergisi, 24(1), 39-53.

Perrow, C. (2014). Complex organizations: A critical essay. Brattleboro, VT: Echo Point Books \& Media.

Robbins, S. P. ve Judge, T. A. (2015). Örgütsel davranış. İ. Erdem (Çev. Ed.). Ankara: Nobel Akademik Yayıncılık.

Sağsan, M. (2006). Bilgi paylaşımı için örgüt içi iletişim kanallarının tasarımına yönelik ipuçları ve öneriler. 1st International Symposium on Information Services Bildiriler Kitabı, İstanbul, ss. 21-34. 13 Mart 2018 tarihinde https://staff.neu.edu.tr/ msagsan/files/PUBL/doc adresinden erişildi.

Scott, W. R. (1987). The adolescence of institutional theory. Administrative Science Quarterly, 32(4), 493-511.

Sergiovanni, T. J. (2009). The principalship: A reflective practice perspective. Boston, MA: Pearson.

Shapiro, A. (2006). Barnard, Chester I. F. W. English (Ed.), Encyclopedia of educational leadership and administration içinde (ss. 100). Thousand Oaks, CA: Sage Publications, Inc.

Şimşek, M. Ş. ve Çelik, A. (2018). Yönetim ve organizasyon. Konya: Eğitim Kitabevi.

Sucu, Y. (2000). Geçmişten günümüze yönetim düşüncesindeki gelişmeler: Bütünleştirici bir durumsallık modeli. Ankara: Elit Yayıncılık.

Watkins, D. (1983). Scientific management and critical theory in education administration. R. Bates (Ed.), Education administration and the management of knowledge içinde (ss. 119-135). Victoria, Australia: Deakin University.

Williamson, O. E. (1990). Chester Barnard and the incipient science of organization. O. E. Williamson (Ed.), Organization theory: From Chester Barnard to the present and beyond içinde (ss. 172-206). New York, NY: Oxford University Press.

Wilson, W. (1887). The study of administration. Political Science Quarterly, 2, 197-222.

Wolf, W. B. (1974). The basic Barnard: An introduction to Chester I. Barnard and his theories of organization and management. Ithaca, NY: ILR Press.

Wolf, W. B. (1994). Understanding of Chester I. Barnard. International Journal of Public Administration, 17, 1035-1069.

Wren, D. A. (2010). Barnard. American national biography. Oxford: Oxford University Press. 5 Şubat 2019 tarihinde http://www.anb.org/view/10.1093/anb/9780198606697.001.0001/anb-9780198606697-e-1000098 adresinden erişildi.

Wren, D. ve Bedeian, A. (2009). The evolution of management thought. Westford, MA: John Wiley \& Sons, Inc.

Yauch, W. A. (2010). Improving human relations in school administration. Charleston, SC: Nabu Press.

Yearley, C. K. (2015). Barnard publishes the functions of the executive. New Jersey: Salem Press Encyclopedia. 